\title{
ENTRAINMENT CHARACTERISTICS OF UNSTEADY SUBSONIC JETS
}

\author{
M. F. Platzer \\ U. S. Naval Postgraduate School, Monterey, California \\ and
}

J. M. Simmons and K. Bremhorst

University of Queensland, Brisbane, Australia

\begin{abstract}
A revised version of this paper was published in the AIAA Journal, Vol. 16, No. 3, pp. 282-284, March 1978. Permission to include in the workshop proceedings has been granted by AIAA.
\end{abstract}




\section{INTRODUCTION}

The entrainment mechanism in turbulent jets has been a subject of conslderable basic and applied interest for many years. Recently, this problem has received increased attention because of the need to develop compact, yet. highly efficient thrust augmenting ejectors for VSTOL applications ${ }^{1}$. Several new techniques have been introduced or proposed to increase the jet entrainment e.g., hypermixing ${ }^{2}$, swirling $^{3}$, acoustic interaction ${ }^{4}$ and unsteady jet techniques $^{5}$. It is the objective of this paper to present recent results on the cntrainment characteristics of two types of unsteady jet flows, $i . e$. , oscillating jets with time-varying jet deflection and pulsating jets with tine-varying mass flow.

The use of oscillating jets for enhanced flow entrainment was first advocated by Viets ${ }^{5}$ who also developed a rather ingenious fluidic jet actuation device. Other oscillating jet studies have been reported $6,7,8,9$ but they do not contain entrainment measurements.

The favourable effect of pulsating jets on flow entrainment seems to have been first recognized during the development of the pulse jet engine $10,11,12$. Lockwood ${ }^{10}$ also noted the generation of ring vortices due Lo pulsating [low, an effect later verified more clearly by curtet and Cirard ${ }^{13}$. Further pulsating jet studies are those of Johnson and Yang ${ }^{14}$, I) idelle et a1., 15,16, Binder and Favre-Marinet ${ }^{17}$, Crow and Champagne 18 and, very recent 1 y Bremhorst and Harch ${ }^{19}$.

The following section is a report of three different experiments which were cunducted to assess the effectiveness of jet unsteadiness in enhancing, flow all raiment. 


\section{EXPFRIMENTS}

Definition of the edge of a turbulent jet raises subtleties which are discussed by crow and Champagne ${ }^{18}$ in terms of the turbulent (or inner rotational) region and the induced potential flow (or potential tails). In the experiments mean volumetric flow rates $Q(x)$ in the turbulent region of unsteady subsonic jets were determined at a number of distances $x$ from the nozzle by integration of mean jet velocity distributions. A constant temperature hot-wire anemometer was used in all cases and the mean of its linearized output was assumed to be proportional to the mean velocity in the direction of the center line of the nozzle. Errors arising from estimation of the edge of the turbulent region and from the influence of high ratios of rms to mean velocities near the edge of the jet are regarded as tolerabie in this investigation.

Various measures of entrainment are defined in the literature. Here, entrainment is defined as $\left(Q(x)-Q_{R}\right) / Q_{R}$ where $Q_{R}$ is a reference flow rate and is properly taken as the mean volumetric flow rate $Q_{E}$ at the nozzlc exit in two of the experiments. In the third experiment $Q_{R}$ is taken, for 1 ack of precise nozzle flow rate information, as the volumetric flow rate $Q_{1}$ at a stition near the nozzle in a steady jet. This still enables comparisons and is discussed later in more detail. Clearly, the entrainment. differs by unity from the dimensionless local flow rates $Q(x) / Q_{R}$ which are presented in this paper.

Pluidically Oscillated Three-Dimensional Jet

The fluidic nozzle illustrated in figure 1 was used by the first and sccond authors to exhaust a jet of air with oscillating angle into still air. 
The nozzle was based on a design by Viets ${ }^{5}$. Flow from a plenum chamber and a contraction emerges from a $6.2 \times 49.0 \mathrm{~mm}$ rectangular section into a rapid diffusion section where it is bistable because of the proximity of the walls. The flow is illustrated at the moment it attaches to the lower wall $A$. This sets up an entrainment process and generates compression and rarefaction waves in the feedback tube connecting control parts $A^{\prime}$ and $B^{\prime}$. Continuous jet oscillation results at a frequency which depends on the length of the feedback tube.

In both the oscillating and the steady tests the nozzle was operated at a pressure ratio of 1.13 to produce a mean mass flow rate of $0.0188 \mathrm{~kg} / \mathrm{s}$ as measured with an upstream orifice plate. The jet oscillated through about 7 drerees either side of the nozzle centar 1 ine and with a fundamental frequency of $52 \mathrm{~Hz}$. However, higher harmonics were appreciable because of the flip-flop mode of operation. Viets ${ }^{5}$ showed that velocity fluctuations at the half-width pusition of the mean velocity profile have almost a square wave shape.

The values of volumetric flow rate $Q(x)$ used in figure 2 vere obtained by integration of the mean velocity distribution across the jet cross-sections. The limits of integration were stations at which the mean velocity was between 5 and 1.0 percent of the maximum value in a distribution. This necessitated mild extrapolation of the distribution furthest downstream so that the value of $Q(x)$ there has a possible error of about 10 percent. For the two cases of oscillating and fixed jet angle, $Q(x)$ is normalized by the mean volumetric flow rate $Q_{E}$ at the nozzle exit. Mass flow rate upstreall of the nozzle (measured with an orifice plate) was used to determine $Q_{\mathrm{F}}$. The hydraulic diameter of the nozzle (4 x area/perimeicr) i:i used as the length scale because of the essentially three-dimensional 
nature of the flow. The change in slope of the curve of $Q(x) / Q_{E}$ for the steady jet is attributed to the transition from a high aspect ratio threedimensional flow to a more axisymmetric mean flow.

Mechanically Oscillated Two-Dimensional Jet

Recent two-dimensional studies of flow past an airfoil at zero incidence and with an oscillating trailing edge jet flap have been extended by the first. and second authors to measurements of entrainment. Details of the mechanically oscillated nozzle have been reported previously ${ }^{9,20}$. In these tests the nozzle was oscillated through 5.2 degrees either side of the airfoil chordline and at frequencies of 4 and $20 \mathrm{~Hz}$. The free stream velocity was $29.2 \mathrm{~m} / \mathrm{s}$ and the nozzle exit velocity of $137 \mathrm{~m} / \mathrm{s}$ was estimated, using the results of Bradbury and $\mathrm{Riley}^{21}$, from measurements of the velocity profile close to the nozzle with the jet held parallel to the free-stream.

The instantaneous velocity profiles measured in a previous study 20 were averaged over a cycle of nozzle oscillation to obtain mean velocity irofiles and hence mean volumetric flow rates. Because nozzle velocity was not measured directly the measurements in figure 3 for the oscillating and the steady cases are both normalized by the volumetric flow rate in the steady jet across the measuring section nearest the nozzle (i.e. 35 nozzle widths downstream). The use of a small nozzle width $(0.38 \mathrm{~mm})$ and measurtng; stations many nozzle widths downstream is a legacy of the preceding studies of jet flaps and leads to an uncertainty in $Q(x) / Q_{1}$ which increases to about 10 percent at the downstream limit. Nevertheless, the measured insensitivity of $Q(x) / Q_{1}$ over the range of $x$ to the frequency of oscillation iss significant. It must be stressed that the jet flowed into a moving airst. ream. 


\section{Axisymmetric. Jet with Pulsed Core}

Bremhorst and Harch ${ }^{19}$ recently studied a fully pulsed axisymetric air jet exhausting into still air and their measurements of $Q(x) / Q_{E}$ are reproduced in figure 2. They used a mechanical valve connected to a plunum chamber by a smooth transition piece. The valve allowed flow for one third of its period of cyclic operation. The first and third authors used the same valve to study an axisymetrlc air jet flowing into still air but with pulsation restricted to the inner core by the fitting of a two-stream conxial nozzle downstream of the valve (figure 1). The nozzle consisted of a central reducer with $6.9 \mathrm{~mm}$ exit diameter to which air was supplied solely from the pulsating valve, and an annular section of $25.4 \mathrm{~mm}$ diameter which was fed through a regulating valve with air taken from upstream of the plenum chamber.

The total jet flow rate was measured with a flow meter well upstream of the plenum chamber. The inner coaxial jet flow rate for the pulsed core was; metered separately upstream of the plenum chamber. The mean exit velocities for the steady annular portion of the jet and the pulsed core were 18.3 and $12.6 \mathrm{~m} / \mathrm{s}$ respectively.

The results in figure 2 were obtained by planimeter integration of the radius times local mean velocity versus radius profiles. These profiles were raired to zero in order to exclude the potential tails as was done by Cruw and champagne ${ }^{18}$. The total volumetric flow rate across a downstream section was then normalized by the mean volumetric flow rate at the nozzle exit. Measurements by Crow and Champagne ${ }^{18}$ for a steady axisymmetric jet are prosented for conparison. 


\section{DISCUSSION}

The results in figure 2 show the powerful effect of full jet pulsation on entrainment. Also, the entrainment is seen to increase with frequency, but measurements are avallable for only two frequencles. Pulsation of only the jet core still provides significant entrainment benefits over the steady jet (figure 2) and this method can be regarded as an entrainment control device which enables the setting of the desired entrainment level for a jet of given flow rate. The fluidically oscillated jet shows equally significant entrainment increases (up to 55 percent increase in $Q(x) / Q_{E}$ at the most downstream station) when compared in figure 2 with the steady jet. Similar results with the same fluidic nozzle operated at a higher pressure ratio (1.33) were obtained by jeltman ${ }^{22}$ with a cruder measuring technique (pitot-static tube). Finally, in figure 3 the volumetric flow rate measurements for the sinusoidally oscillated jet flap show negligible variation from the corresponding steady jet measurements. This indicates that any significant influence of jet oscillation on the entrainment processes must, if it exists, be confined to the as yet uninvestigated vicinity of the nozzle.

These results indicate that entrainment depends on the type and amount of jet unsteadiness. Apparently the mere introduction of jet unsteadiness by small sinusoidal flow angle variations is insufficient to enhance entrainment but it should be noted that the results in figure 3 were obtained at measuring stations which are all many nozzle widths downstream of the jet nozzle. Thus, no fully conclusive statement can be made at this time about the entrainment close to the nozzle. However, the measuring stations for the sinusoidally oscillated jet were all within less than one half of 
the jet wave length. Therefore, the sinusoidally oscillated jet was operated at a much smaller reduced frequency than the other two jets. In effect, it approdched quasi-steady conditions which may well explain its low entrainnent. Indeed, in two previous papers 20,23 it was shown that quasi-steady concepts are quite successful in explaining the major flow features.

The high entrainment of the fluidically oscillated jet would appear to be caused by the high-frequency content of this square wave type of oscillation but more detafled measurements are clearly needed, in particular for the fluidically oscillated and the pulsed jets. Such studies are presently in progress. Furthermore, practical ejector application requires the proper trade-off between entrainment and primary nozzle thrust efficiency. While: some information is available on the thrust efficiency ${ }^{5,22}$ of the fluidic nozzle there seems to be none available for pulsating nozzles. 
REFFERECES

1. Schum, E. F., "Techniques for Increasing Jet Entrainment Rates in Ejector Augmenters," Proceedings of the Workshop on Prediction Methods for Jet V/STOL Propulsion Aerodynamics, Naval Air Systems Command, July 1975, pp. 639-652. (available from DDC as AD-A024023) .

2. Quinn, B., "Compact Ejector Thrust Augmentation," J. Aireraft, Vo1. 10, Aug 1973, pp. 481-486.

3. Chigier, N. A. and Chervinsky, A., "Experimental and Theoretical. Study of Turbulent Swirling Jets Issuing from a Round Orifice," Israel $J$. T'echnology, Vol. 4, Feb 1966, pp. 44-54.

4. Hi11, W. and Greene, P., "Self-Excited Superturbulence: The Whistler Nozzlc," Grumman Research Department Rep. No. RE-488, oct 197/, (available from DDC as AD-A001021).

5. Viets, H., "Flip-Flop Jet Nozzle," AIAA Joumal, Vol. 13, Oct 1975, pp. $1375-1379$.

6. Trenka, A. R. and Erickson, I. C., Jr., "The Determination of Unsteady Aerodynamics of a Two-Dimensional Jet-Flap Wing," CAL AC-2260-S-1, Cornell Aeronautical Laboratory, Buffalo, NY, April 1970.

7. Kretz, M., "Commande Asservie des Forces Aerodynamiques Instationnaires," De: 07-44F5, Giravions Dorland, Suresnes, France, 1973.

8. Simmons, J. M. and Platzer, M. F., "Experimental Investigation of Incompressible Flow Past Airfoils with Oscillating Jet Flaps," $J$. Airerafl, vol. 8, Aug 1971, pp. 587-592.

9. Sinmons, J. M., "Measured Pressure Distribution on an Airforil with Oscillating Jet Flap," AtAA Joumaz, Vol. 24, Sept 1976, ppn 1297-1302. 
10. Lockwood, R. M., "Pulse Reactor Lift-Propulsion System Development Program," Hillier Aircraft Company, Rep. No. ARD-308, March 1963.

11. Foa, J. V., "Intermittent Jets," High-speed Aerodynamics and Jet Propulsions, Vol. XII, Sect. F, Princeton University Press, 1958.

12. Bertin, J., "Dilution Pulsatoire sur Reacteur, C. R. Acad. Soi. Paris, Vo1. 240, 1955, pp. 1855-1857.

13. Curtet, R. M. and Girad, J. P., Visualization of a Pulsating Jet," Proc. of ASME Symposium on Fluid Mechanics of Mixing, At.lanta, GA., June 1973, pp. 173-180.

14. Johnson, W. S. and Yang, T., "A Mathematical Model for the Prediction of the Induced Flow in a Pulsejet Ejector with Experimental Verification," ASilE Winter Annual Meetirg and Energy Systems Exposition, New York, Paper 68-WA/FE-33, Dec 1968.

15. Didelle, H., Binder, G., Craya, A. and Laty, R., "L'augmentation de 1a poussée d'une trompe à jet inducteur pulsant: Project, installation et mise au point de la soufflerie, de la trompe et du banc de mesure de poussée," Laboratoires de Mécanique des Fluids, Univ. Grenoble, Oct 1971.

16. Didelle, H., Binder, G., Craya, A. and Laty, R., "L'augmentation de la pouske d'une trompe à jet inducteur pulsant: Résultats des essais," Laboratoires de Mécanique des Fluides, Univ. Grenoble, June 1972.

1\%. Binder, G. and Favre-Marinet, M., "Mixing Improvement in Pulsating Turbulent Jets," Proo. ASWE Symposium on Fluid Mechanias of llixing," Atlanta, GA., June 1973, pp. 167-172.

18. Crow, S. C. and Champagne, F. H., "Orderly Structure in Tet Turbulence," J. liludd Mech., Vol. 48, Aug, 1971, pp. 547-591. 
19. Bremhorst K. and Harch, W. H., "Near Field Velocity Measurements in a Fully Pulsed Subsonic Air Jet," Symposium on Turbulent Shear Flows, Pennsylvania State University, April 1977.

20. Simmons, J. M., Platzer, M. F. and Smith, T. C., "Velocity Measurements in an Oscillating Plane Jet Issuing into a Moving Airstream," J. Fluid Mech., vol. 84, part 1, np. 33-53, 1978.

21. Bradbury, L. J. S., and Riley, J., "The Spread of a Turbulent Plane Jet Issuing into a Parallel Moving Airstream," J. Fluid Mech., Vo1. 27, Feb 1967, pp. 381-393.

22. Veltman, R. J., "An Experimental Investigation of the Efficiency and Entrainment Rates of a Fluidically Oscillated Jet," Master's Thesis, U. S. Naval Postgraduate School, June 1976.

23. Simmons, J. M. and Platzer, M. F., "A Quasi-steady Theory for Incompressible Flow Past Airfoils with Oscillating Jet Flaps," AIAA Journa1, Vo1. 16, No. 3, op. 237-241, March 1978. 

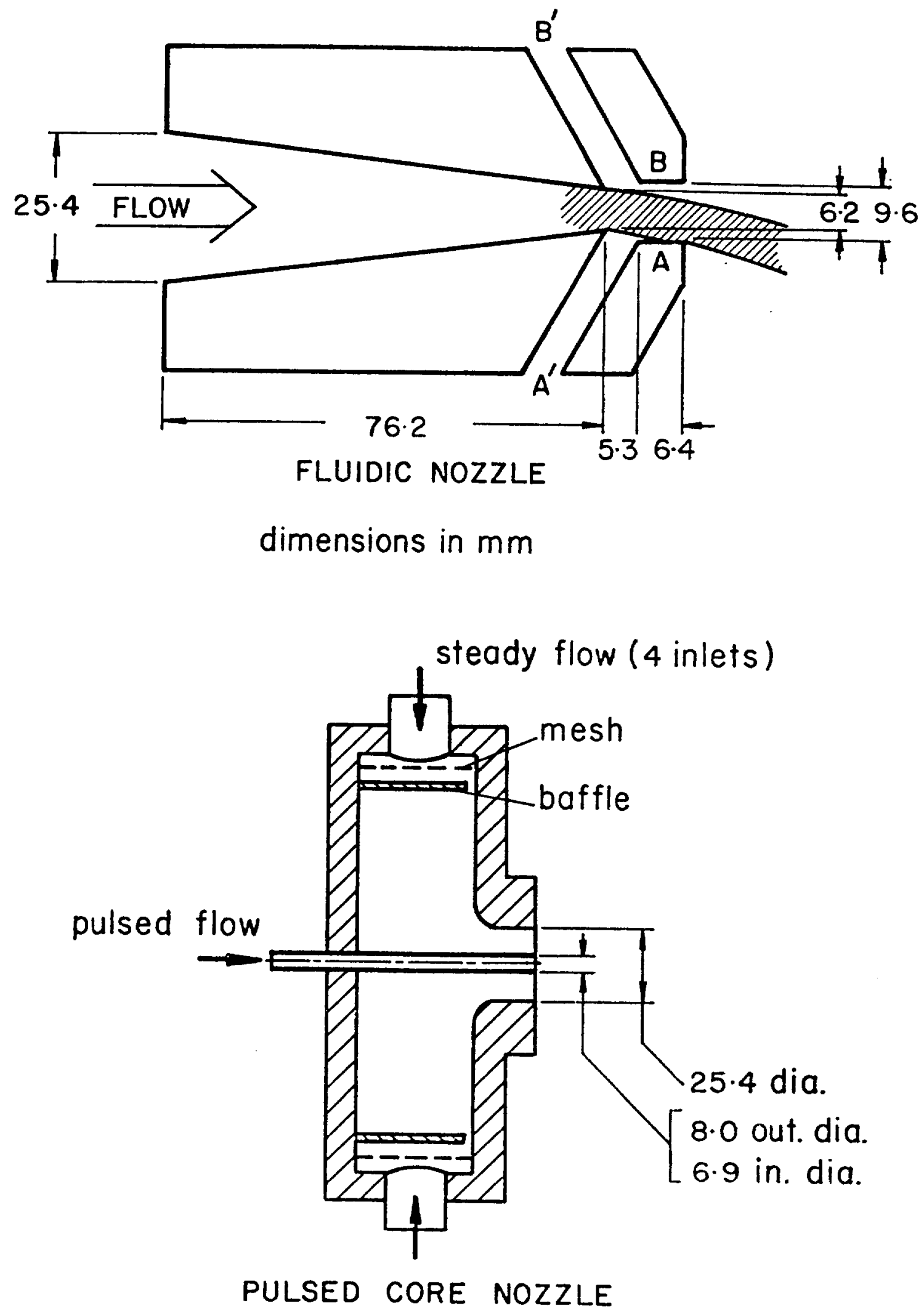

Figure 1. Schematic of fluidic and pulsed core nozzles.

322 


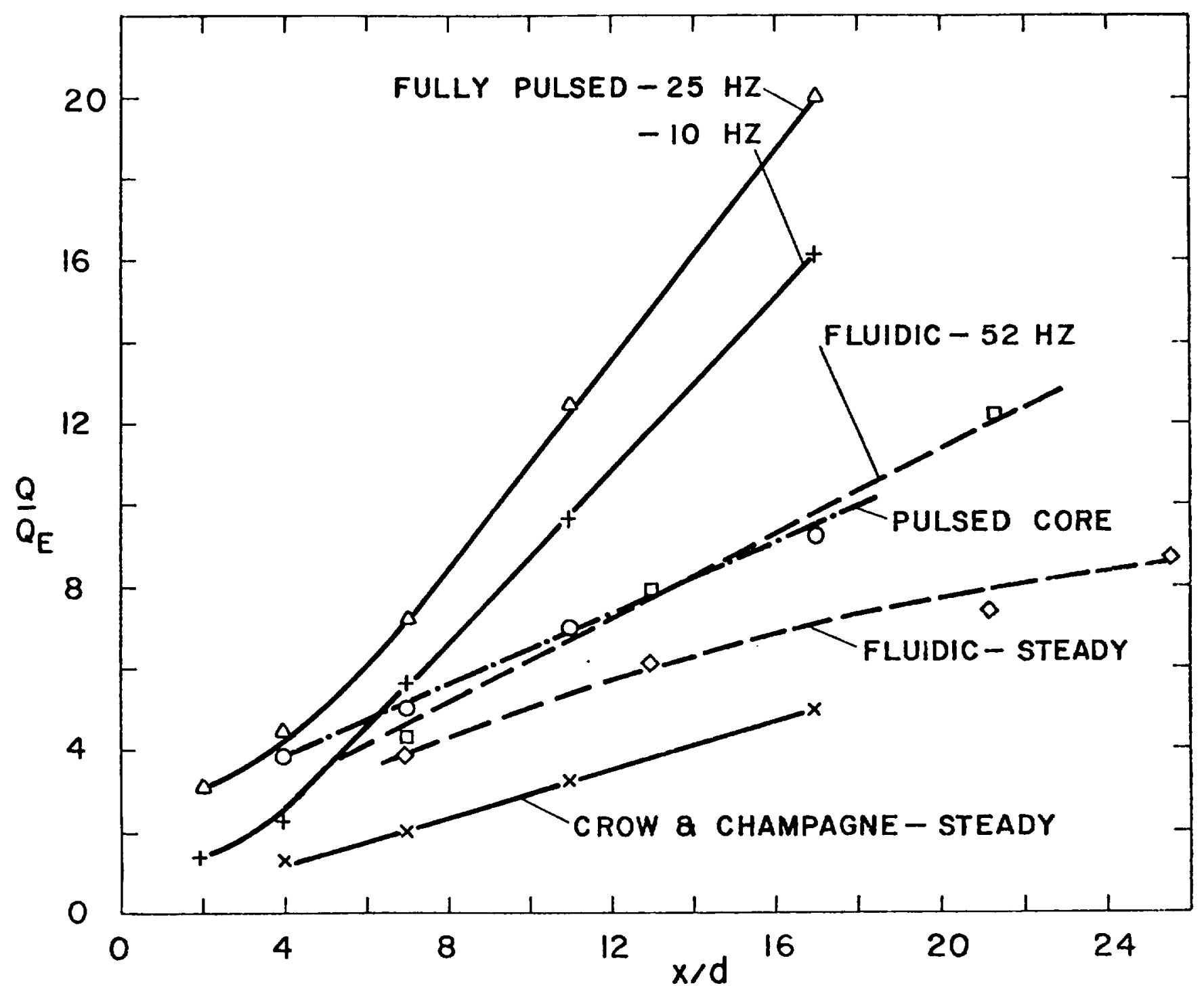

Figure 2. Mean volumetrlc flow rates $\eta(x)$ versus streamise distance $x$ for fluidic, fully pulsed and pulsed core nozzles. $\mathrm{P} F$, is mean nozzle exit fluw. $d$ is hydraulic diameter of fluidir nozzle: or diameter of axisymmetric nozzles. 


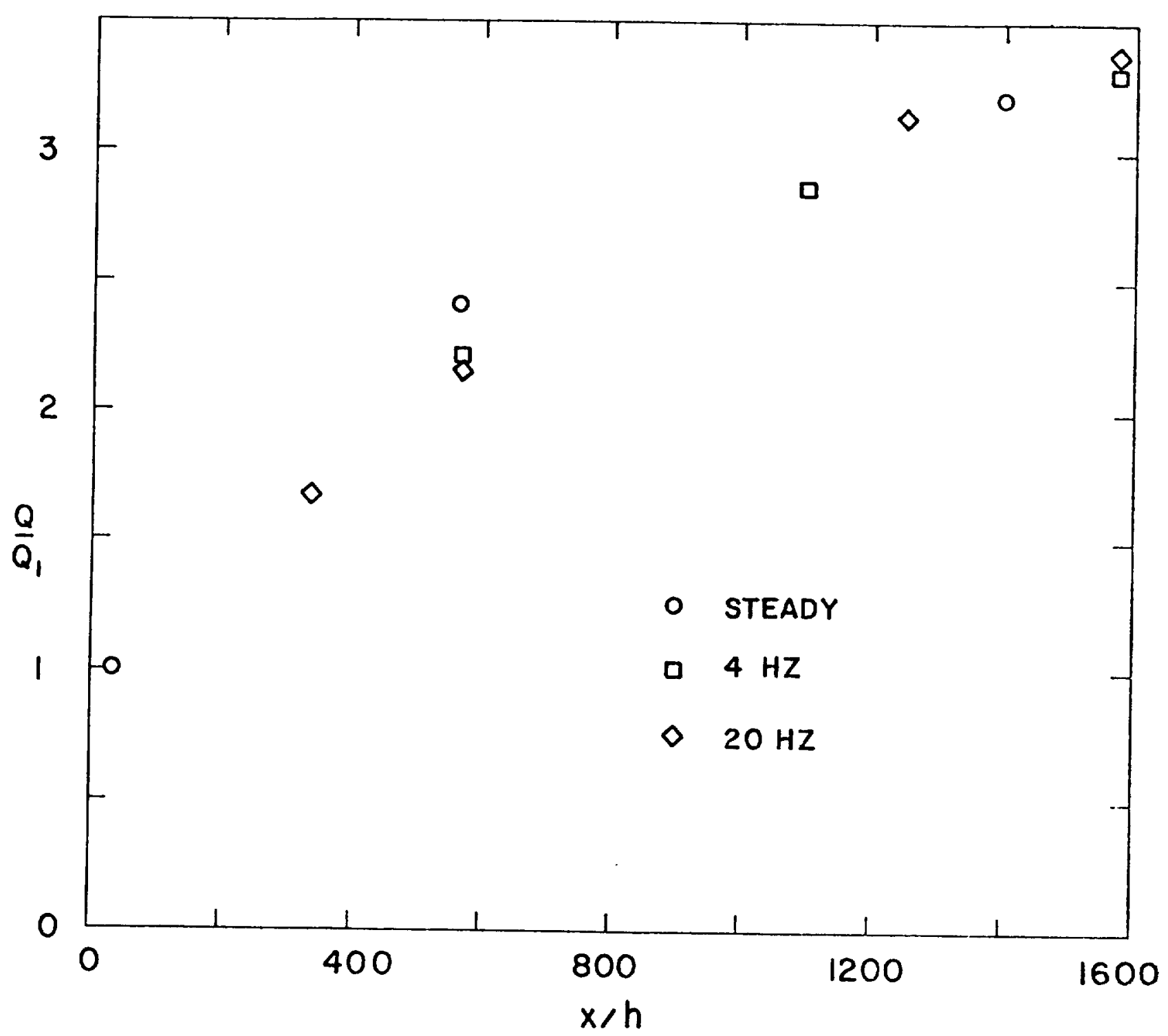

Figure 3. Mean volumetric: flow rates $Q(x)$ versus streamalse distance $x$ for mechanically oscillated two-dimensional jet. $?_{1}$ is flow in steady jet at $x / h=35$. $h$ is nozzle width. 